\title{
Mapping Global Risk of Heatwave Mortality Under Climate Change
}

\author{
Qinmei Han, Weihang Liu, Wei $\mathrm{Xu}$, and Peijun Shi
}

\section{Background}

Global warming has become a severe problem worldwide, where the average global temperature has steadily increased over recent decades accompanied by the abnormally hot weather (IPCC 2013). Since the 1950s, heatwave events have increased in frequency, intensity, and duration and their impact on human health will also increase under enhanced global warming (Perkins-Kirkpatrick and Lewis 2020). Heatwaves have become one of the most serious climate events in the world. Exposed to heatwave is associated with increasing mortality - for instance, the European heatwave of 2003 induced more than 70,000 additional deaths in France, Germany, Italy, Spain, and other countries (Robine et al. 2008). For Russia as a whole, the death toll of the 2010 summer heatwave totaled 55,000 people (Barriopedro et al. 2011).

Considering the ever-worsening impact of heatwaves, future projection of heat-related mortality under climate change has been widely studied in recent decades. Heatwave mortality shows an increasing trend under high-emission scenarios (Huang et al. 2011), especially in temperate areas (Gasparrini et al. 2017). Existed studies mainly focus on regional-, country-, or city-level risk assessments, but the distribution and variation of heatwave mortality risk at a

Authors: Qinmei Han, Weihang Liu, Wei Xu, Peijun Shi. Map Designers: Xinli Liao, Jing'ai Wang, Ying Wang. Language Editor: Wei Xu.

Q. Han $\cdot$ W. Liu $\cdot$ W. Xu $\cdot$ P. Shi $(\bowtie)$

Faculty of Geographical Science, Beijing Normal University, Beijing, 100875, China

e-mail: spj@bnu.edu.cn

W. Xu · P. Shi

State Key Laboratory of Earth Surface Processes and Resource

Ecology, Beijing Normal University, Beijing, 100875, China global scale need to be further quantitatively evaluated. Mapping heat-related mortality and finding the hotspots will help provide the policy recommendations at both global and national levels.

This study examined future heatwave mortality risk of the world at the grid level $\left(0.25^{\circ} \times 0.25^{\circ}\right)$ and country level, respectively, based on the disaster system theory (Shi 1991, 1996, 2002), using the data of temperature and population changes. We also evaluated the decadal mortality risk change in the 2030s (2016-2035) and the 2050s (20462065) as compared to the baseline period (1986-2005) using high spatial resolution climate and population data under different Representative Concentration Pathway (RCP) and Shared Socioeconomic Pathway (SSP) scenarios, namely RCP2.6-SSP1, RCP4.5-SSP2, and RCP8.5-SSP3. To estimate the regional change, we adopted the regionalization recommended by the Intergovernmental Panel on Climate Change (IPCC), which divides the world into 26 regions.

\section{Method}

In this study, we used daily maximum temperature as the metric to calculate heatwave. The daily maximum temperature data were from the NEX-GDDP dataset, which was released by the National Aeronautics and Space Administration (NASA) in June 2015 (https://dataserver.nccs.nasa. gov/thredds/catalog/bypass/NEX-GDDP/catalog.html). The spatial resolution of the dataset is $0.25^{\circ} \times 0.25^{\circ}$. There are 21 general circulation models in this dataset that contain two RCPs-RCP4.5 and RCP8.5-for the period from 1950 to 2100. The temperature data of lower emissions scenario RCP2.6 was computed by sub-project 1 . The population projection data used in this study contain SSP1 - 3 computed by sub-project 2 . We calculated heatwave intensity and mortality risk for the periods 2016-2035 and 2046-2065 in the future compared to 1986-2005 under the 


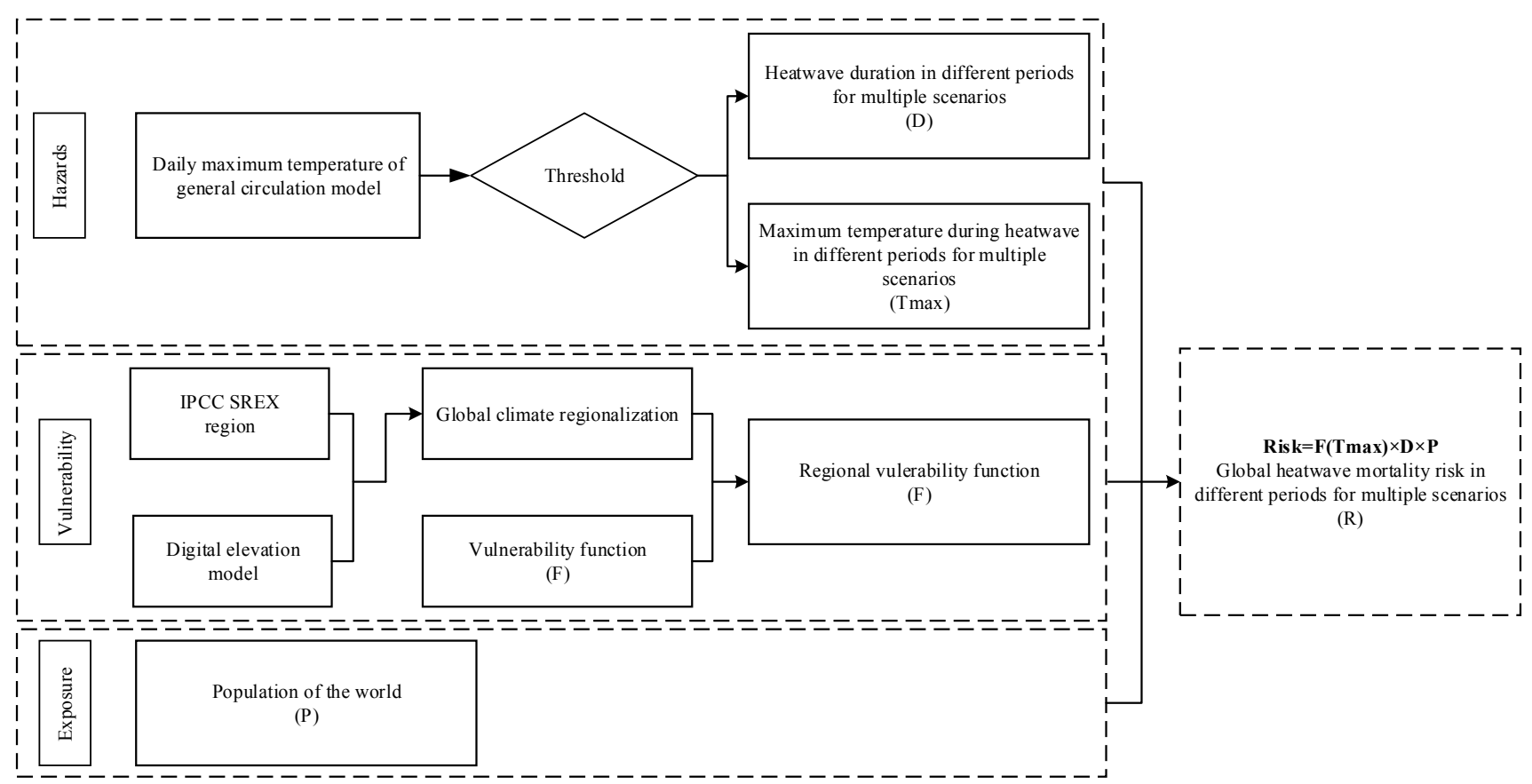

Fig. 1 Technical flowchart for mapping global heatwave mortality risk under climate change

RCP2.6-SSP1, RCP4.5-SSP2, and RCP8.5-SSP3 scenarios (Fig. 1). The maps shown in section 4 are multi-model ensemble results.

\subsection{Heatwave Intensity Metrics}

To better estimate regional changes of heatwave mortality risk in the world, we chose a relative threshold instead of an absolute threshold. A heatwave event here was defined as at least three consecutive days exceeding the given threshold, which is the 95th percentile value of the daily maximum temperature series over the baseline period 1986-2005 at the grid level, and if the 95th percentile value was lower than $25{ }^{\circ} \mathrm{C}$, we set $25^{\circ} \mathrm{C}$ as the threshold in this grid. The annual heatwave duration was defined as the total heatwave days in a given year. The annual heatwave maximum temperature was defined as the maximum temperature of all the heatwave events in a year.

\subsection{Population Vulnerability}

In this study, six mortality vulnerability curves for typical cities in the world were adopted (Gosling et al. 2007). In the IPCC-SREX reports, the world is divided into 26 regions
(Seneviratne et al. 2012). We regrouped the 26 regions into 6 groups according to climate types, latitude zones, and terrain elevation. Each vulnerability curve was applied to a group of the IPCC-SREX regions to map heatwave mortality risk of the world.

\subsection{Mortality Risk Function}

Heatwave mortality risk of the world is assessed with formula (1):

$$
R=F\left(T_{\max }\right) \times D \times P
$$

where $R$ is the annual heatwave mortality risk, $F$ represents the regional vulnerability function, $T_{\max }$ refers to the annual maximum temperature during heatwaves, $P$ refers to the annual total population of each grid, and $D$ is the annual heatwave duration (days). We computed the annual heatwave mortality risk for the selected periods-19862005, 2016-2035, and 2046-2065. To map the spatial distribution, we then computed the 20 -year average value for each period. All calculations, analyses, and the figures of the meteorological metrics and heatwave mortality risk were performed and mapped at the grid level $\left(0.25^{\circ} \times 0.25^{\circ}\right)$. 


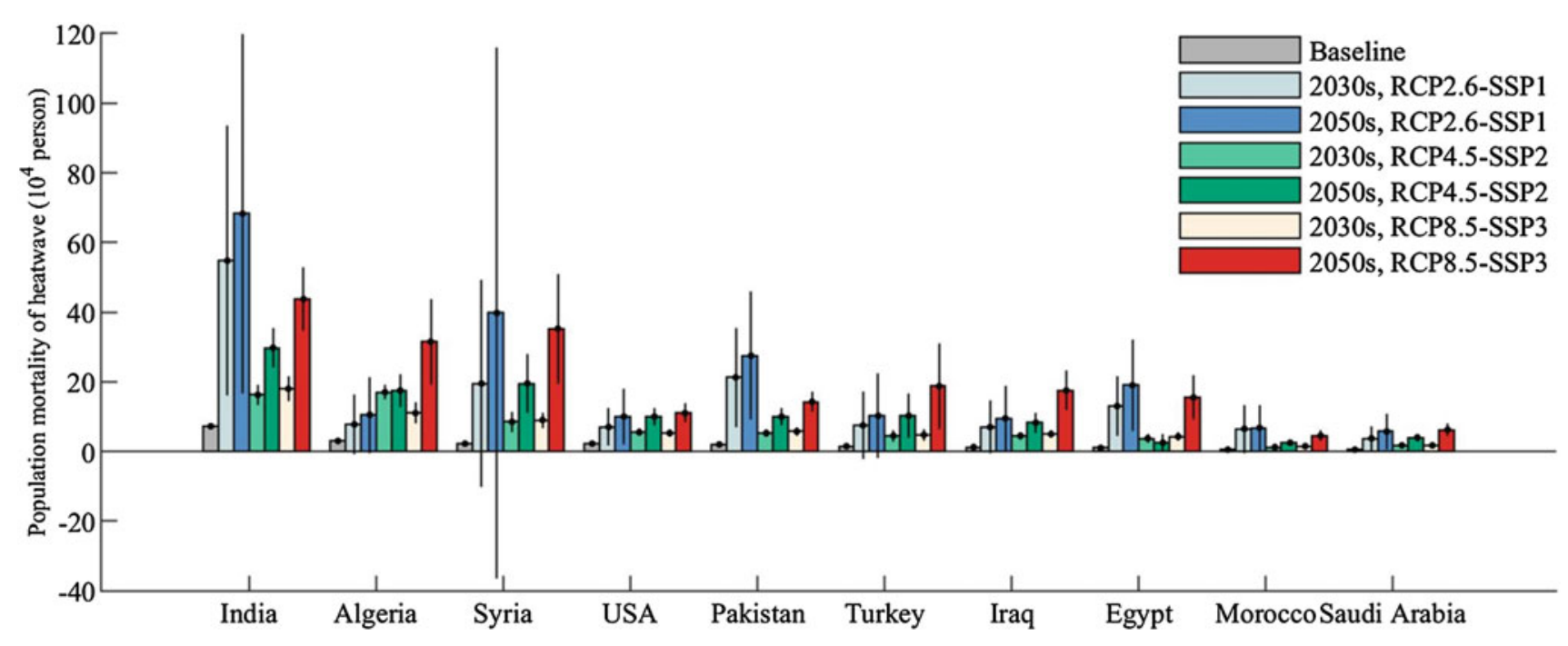

Fig. 2 Heatwave mortality risk of the top 10 countries. The error bar represents the one standard deviation across the 21 (13 for Representative Concentration Pathway (RCP) 2.6) general circulation models and 3 shared socioeconomic pathways (SSPs)

\section{Results}

\subsection{Heatwave Intensity}

The results show that the spatial distribution of heatwave mortality risk for the two periods (2030s and 2050s) under the three scenarios (RCP2.6-SSP1, RCP4.5-SSP2, and RCP8.5-SSP3) are very similar. For the maximum temperature during heatwaves, regions with high values are distributed in North Africa, West Asia, India, and Oceania, mainly near $23^{\circ} \mathrm{N}$, and the temperature decreases from the high value areas to the north and south, respectively.

Heatwave duration decreases from the equator to the poles. The highest duration areas include Central Africa, West Asia, Central Asia, Central South America, and Oceania. The longest heatwave days are in Central Africa, Indonesia, and northern South America. The areas with high values in the 2050s are significantly larger than that in the 2030s under different scenarios.

Generally, global averaged heatwave duration during 1986-2005 are under 10 days per year, whereas it increases to 28 days per year in the 2050s under the high-emission scenarios.

\subsection{Mortality Risk}

High mortality risk areas for heatwaves are mainly distributed in the Northern Hemisphere including India peninsula, West Asia, the Mediterranean area, and eastern North America at the grid level. High latitudes in the Northern Hemisphere are mainly of lower risk as compared to the other regions. Overall, global heatwave mortality risk for the baseline period (1986-2005) is about 289,576 persons per year. In comparison, the annual average heatwave mortality risk increases by 8 times, 5 times, and 8 times in the 2050s under the RCP8.5-SSP3, RCP4.5-SSP2, and RCP2.6-SSP1scenarios, respectively.

We performed the zonal statistics analysis of the risk result at the continental level and the results show a substantial increase during the 2050s under the RCP8.5-SSP3 scenario. The heatwave mortality risk increases by 10 times in Africa followed by 8 times in Asia and 6 times in South America. There are 4-times, 4-times, and 3.5-times increase of heatwave mortality risk in Europe, North America, and Oceania, respectively, in the 2050s under the RCP8.5-SSP3 scenario.

The heatwave mortality risk at the country scale was also derived and ranked. The top ten countries with high heatwave mortality are showed in Fig. 2. These countries are mainly located in North Africa and West Asia, distributed around $30^{\circ} \mathrm{N}$. Compared to the baseline period, the heatwave mortality risks of all countries increase significantly under different scenario combinations, especially in the 2050s (Fig. 2). 


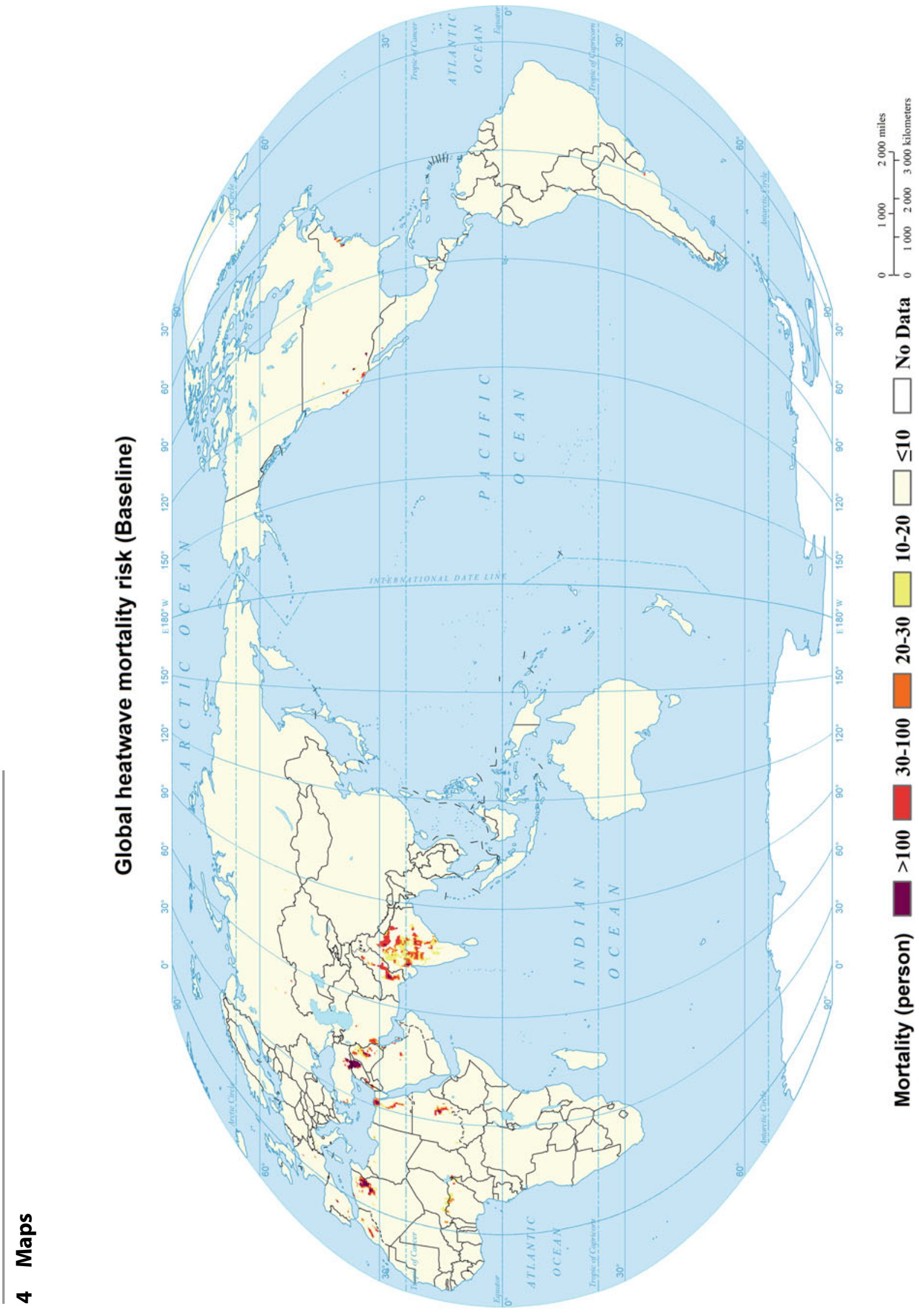


Global heatwave mortality risk (2030s, RCP2.6-SSP1)

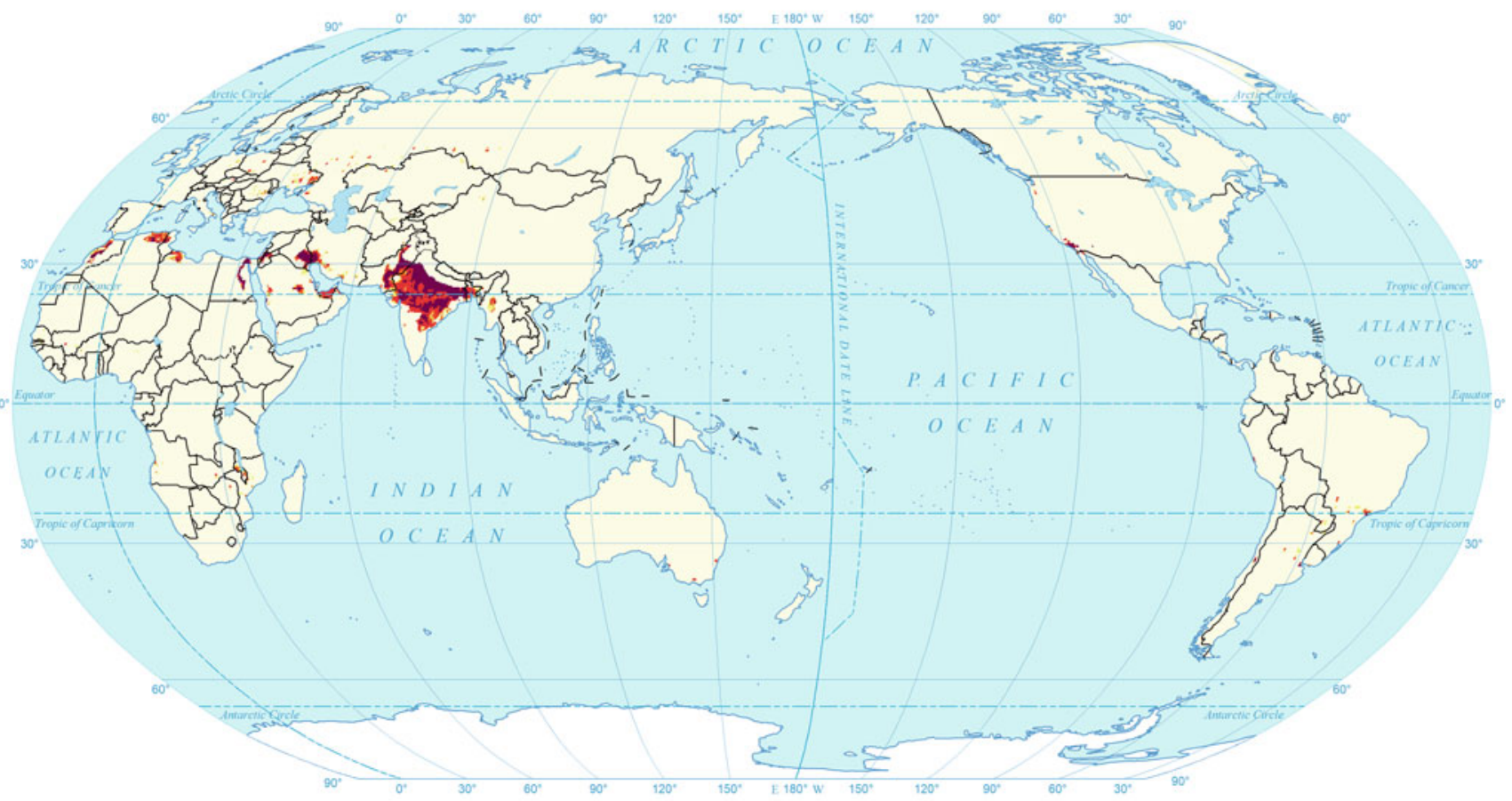

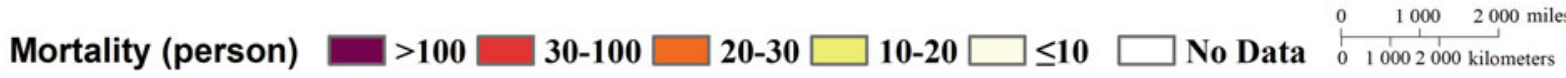

Global heatwave mortality risk (2030s, RCP4.5-SSP2)

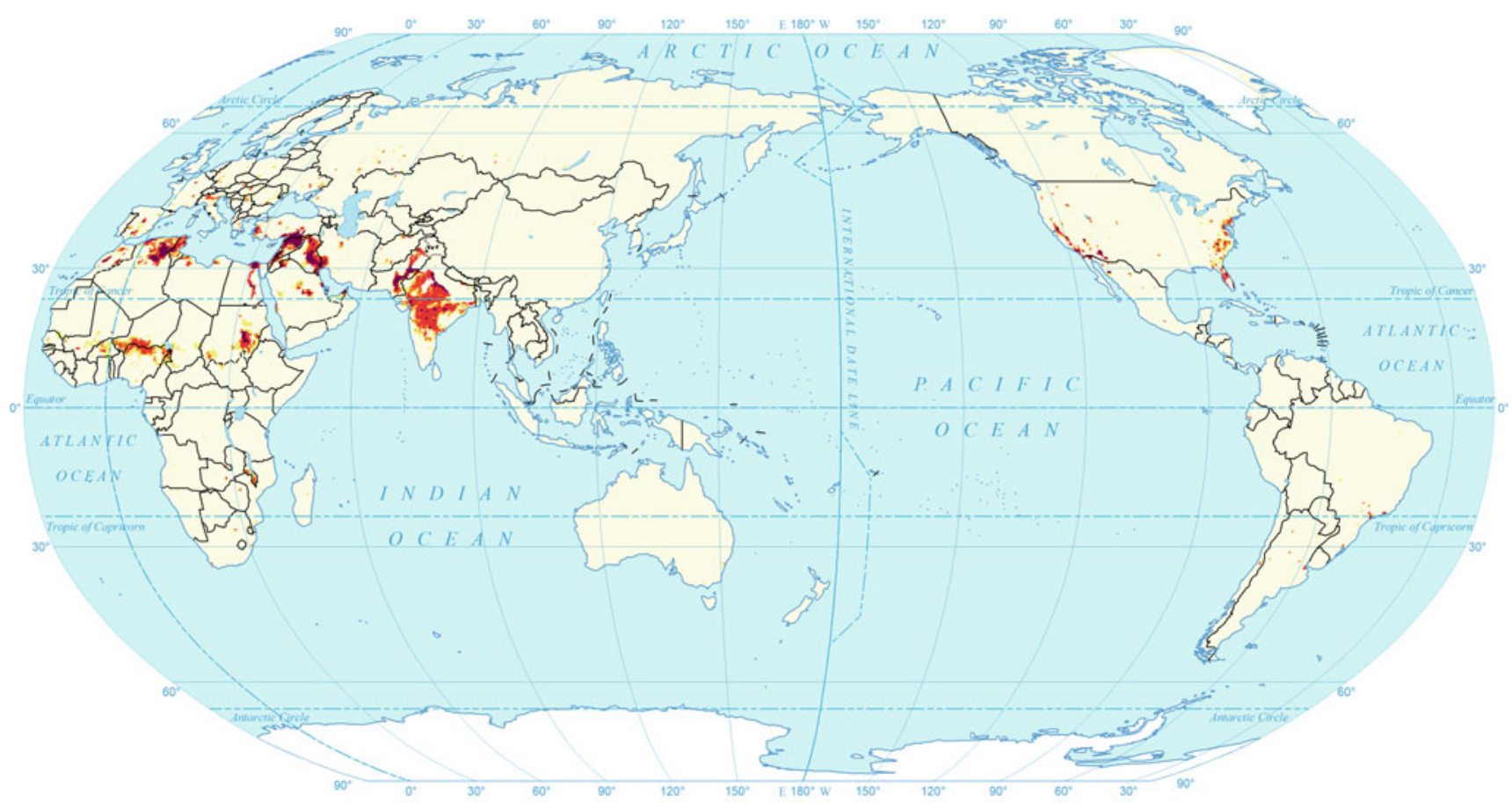

Mortality (person) $\square>\mathbf{1 0 0} \square \mathbf{3 0 - 1 0 0} \square \mathbf{2 0 - 3 0} \square \mathbf{1 0 - 2 0} \square \leq \mathbf{1 0} \square$ No Data $\begin{aligned} & 0 \\ & \stackrel{1}{1} \quad \square 002000 \text { kilometers }\end{aligned}$ 


\section{Global heatwave mortality risk (2030s, RCP8.5-SSP3)}

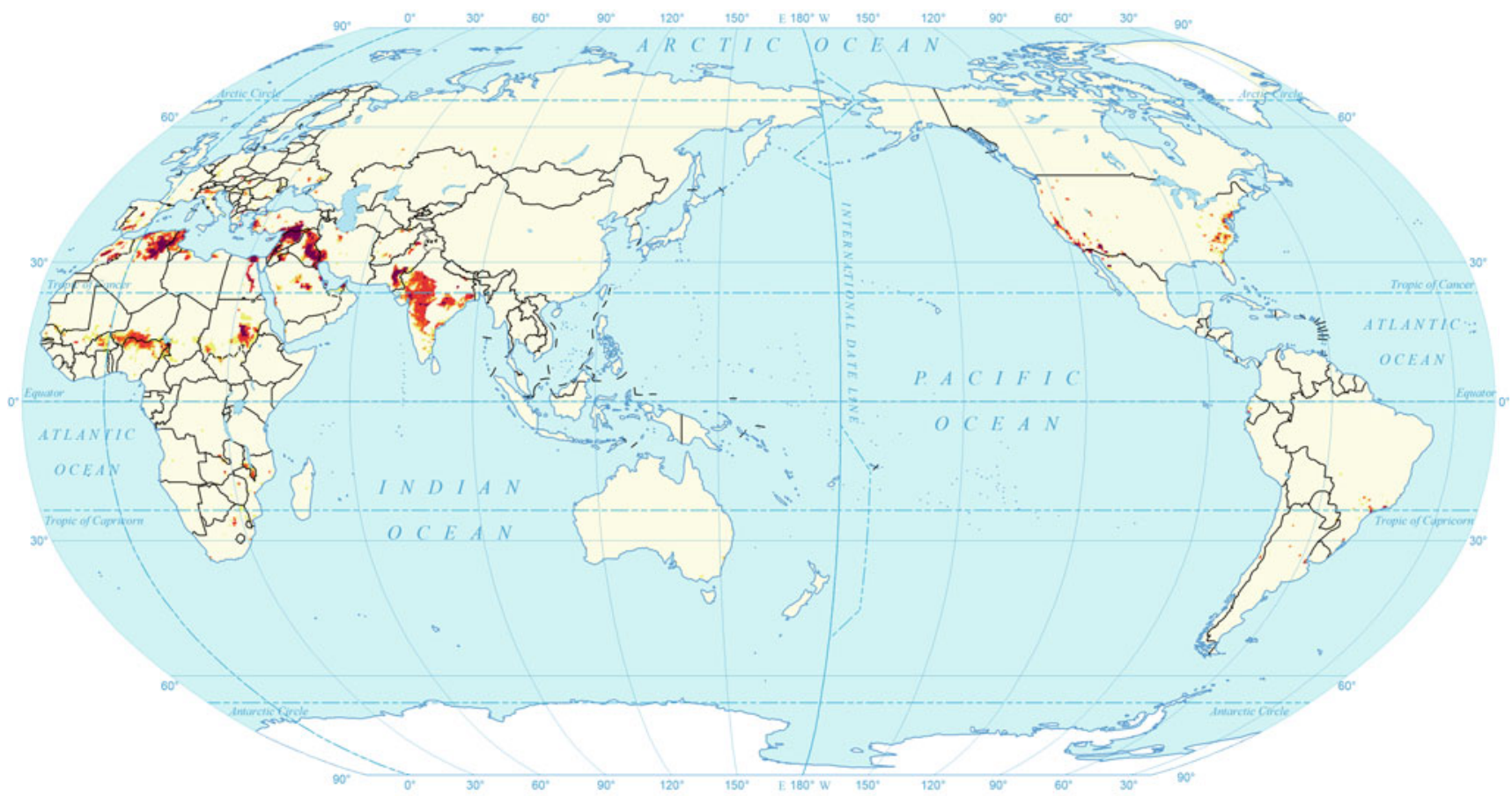

Mortality (person) $\square>\mathbf{1 0 0} \square \mathbf{3 0 - 1 0 0} \square \mathbf{2 0 - 3 0} \square \mathbf{1 0 - 2 0} \square \leq \mathbf{1 0} \square$ No Data $\begin{gathered}0 \quad 1000 \quad 2000 \text { miles } \\ 0 \quad 10002000 \text { kilometers }\end{gathered}$

Global heatwave mortality risk (2050s, RCP2.6-SSP1)

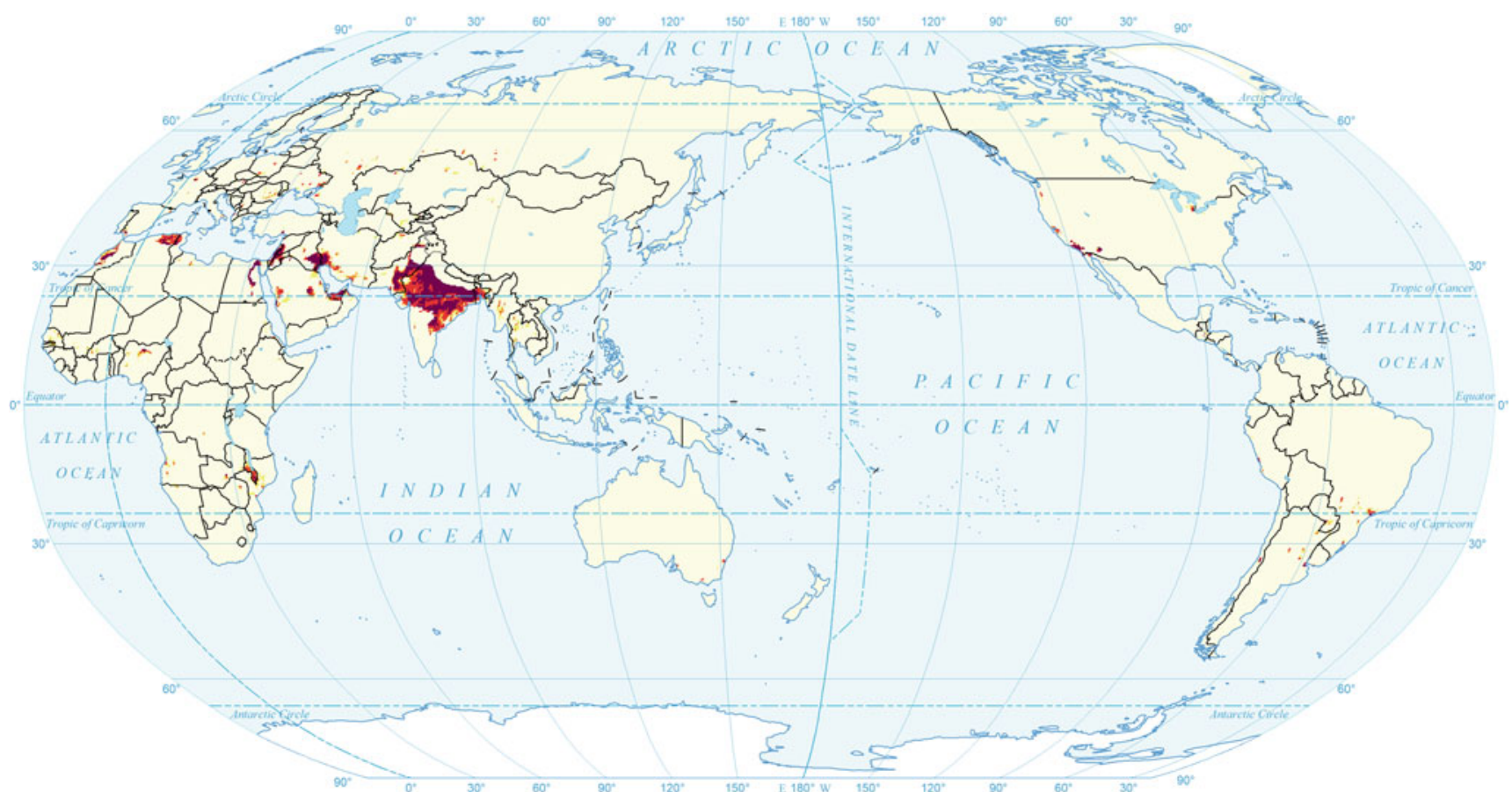


Global heatwave mortality risk (2050s, RCP4.5-SSP2)

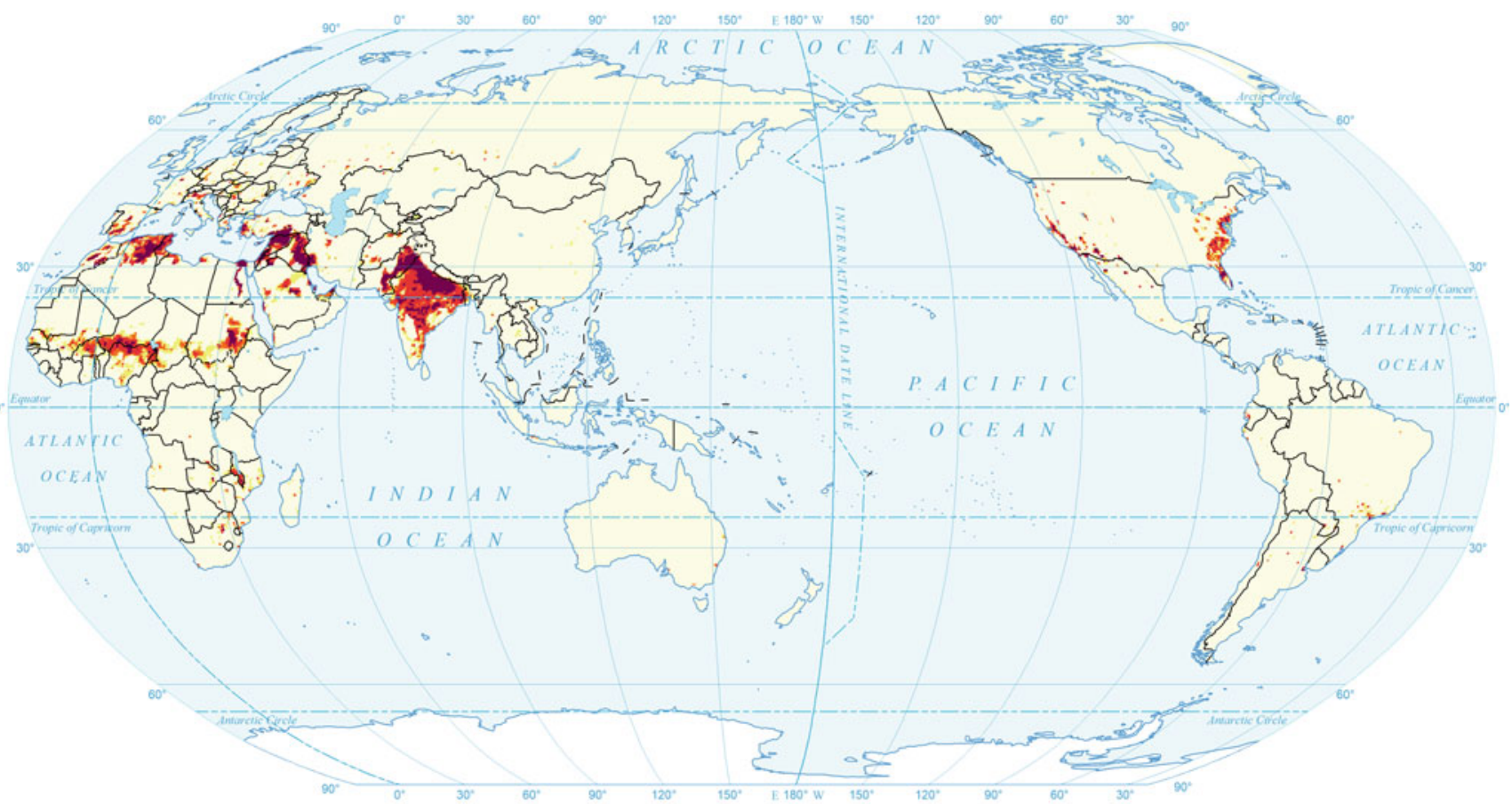

Mortality (person) $\square>\mathbf{1 0 0} \square \mathbf{3 0 - 1 0 0} \square \mathbf{2 0 - 3 0} \square \mathbf{1 0 - 2 0} \square \leq \mathbf{1 0} \square$ No Data $\begin{aligned} & 0 \\ & \stackrel{0}{1} 10002000 \text { kilometers }\end{aligned}$

Global heatwave mortality risk (2050s, RCP8.5-SSP3)

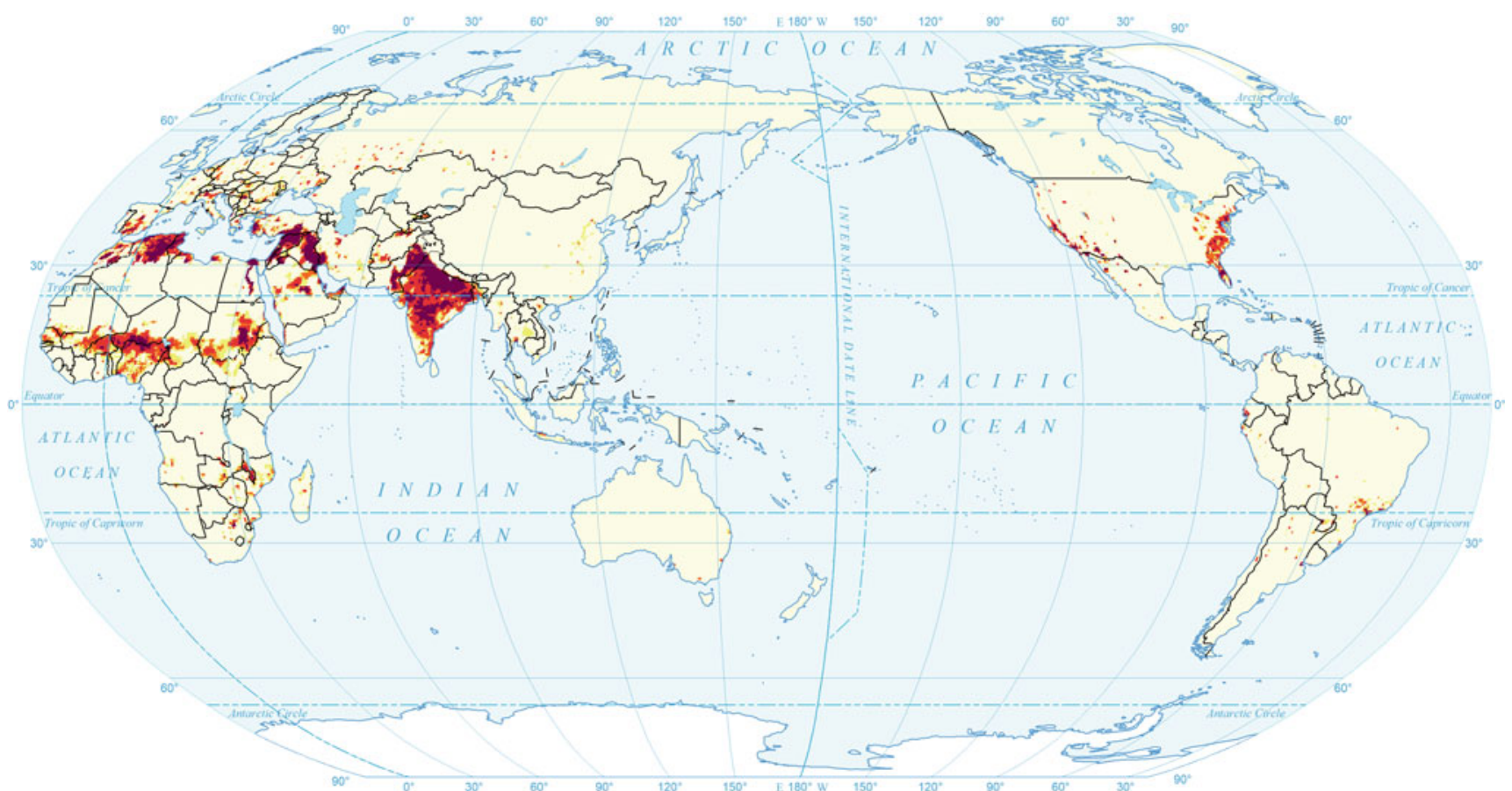

Mortality (person) 


\section{References}

Barriopedro, D., E.M. Fischer, J. Luterbacher, R.M. Trigo, and R. Garcia-Herrera. 2011. The hot summer of 2010: Map of Europe. Science 332 (April): 220-224.

Gasparrini, A., Y. Guo, F. Sera, A.M. Vicedo-Cabrera, V. Huber, S. Tong, M.S.Z.S. Coelho, P.H.N. Saldiva, et al. 2017. Projections of temperature-related excess mortality under climate change scenarios. The Lancet Planetary Health 1 (9): e360-e367.

Gosling, S.N., G.R. McGregor, and A. Páldy. 2007. Climate change and heat-related mortality in six cities Part 1: Model construction and validation. International Journal of Biometeorology 51 (6): $525-540$.

Huang, C., A.G. Barnett, X. Wang, P. Vaneckova, G. FitzGerald, and S. Tong. 2011. Projecting future heat-related mortality under climate change scenarios: A systematic review. Environmental Health Perspectives 119 (12): 1681-1690.

IPCC (Intergovernmental Panel on Climate Change). 2013. Summary for policymakers. In Climate change 2013: The physical science basis. Cambridge, UK: Cambridge University Press.
Perkins-Kirkpatrick, S.E., and S.C. Lewis. 2020. Increasing trends in regional heatwaves. Nature Communications 11 (1): 1-8.

Robine, J.M., S.L.K. Cheung, S. Le Roy, H. Van Oyen, C. Griffiths, J. P. Michel, and F.R. Herrmann. 2008. Death toll exceeded 70,000 in Europe during the summer of 2003. Comptes Rendus Biologies 331 (2): 171-178.

Seneviratne, S.I., N. Nicholls, D. Easterling, C.M. Goodess, S. Kanae, J. Kossin, Y. Luo, J. Marengom, et al. 2012. Changes in climate extremes and their impacts on the natural physical environment. In Managing the risks of extreme events and disasters to advance climate change adaptation: A special report of the intergovernmental panel on climate change, 9781107025, 109-230. https://doi. org/10.1017/CBO9781139177245.006.

Shi, P.J. 1991. Study on the theory of disaster research and its practice. Journal of Nanjing University (natural Sciences) 11 (Supplement): 37-42 (in Chinese).

Shi, P.J. 1996. Theory and practice of disaster study. Journal of Natural Disasters 5 (4): 6-17 (in Chinese).

Shi, P.J. 2002. Theory on disaster science and disaster dynamics. Journal of Natural Disasters 11 (3): 1-9 (in Chinese).
Open Access This chapter is licensed under the terms of the Creative Commons Attribution 4.0 International License (http:// creativecommons.org/licenses/by/4.0/), which permits use, sharing, adaptation, distribution and reproduction in any medium or format, as long as you give appropriate credit to the original author(s) and the source, provide a link to the Creative Commons license and indicate if changes were made.
The images or other third party material in this chapter are included in the chapter's Creative Commons license, unless indicated otherwise in a credit line to the material. If material is not included in the chapter's Creative Commons license and your intended use is not permitted by statutory regulation or exceeds the permitted use, you will need to obtain permission directly from the copyright holder. 